\title{
MISTURA PRONTA PARA PREPARO DE SOPA COM FIBRA DE FEIJÃO COMUM (Phaseolus vulgaris L.)
}

\section{READY TO PREPARE SOUP WITH FIBER OF COMMON BEAN}

\author{
(Phaseolus vulgaris L.)
}

\author{
Cristiane Bourscheid ${ }^{1}$; Ana Claudia Bedin ${ }^{2}$; Mayara Alves Schroder ${ }^{3}$; Polyanna Silveira Hornung ${ }^{4}$ \\ Ana Claudia Barana ${ }^{5}$; Ivo Mottin Demiate ${ }^{6}$; Deise Rosana Silva Simões ${ }^{7}$ \\ 1, 2, 3, 4, 5, 6, 7 Universidade Estadual de Ponta Grossa - UEPG - Ponta Grossa cristianebourscheid @yahoo.com.br
}

\begin{abstract}
Resumo
Estudos para a extração e caracterização do amido com aproveitamento da fração proteica são realizados com o intuito de agregar valor e ampliar a utilização do feijão. Uma vez que, o processamento do feijão gera subprodutos ricos em fibras e proteínas, o objetivo deste trabalho foi desenvolver uma mistura pronta para sopa, com o aproveitamento dos subprodutos do processo de extração do amido de feijão (Phaseolus vulgaris L.). O planejamento experimental foi elaborado com dez formulações variando os níveis de farelo, tegumento e proteína texturizada de soja (PTS) na mistura. Inicialmente, foi avaliado o efeito na qualidade sensorial das dez formulações. Foram selecionadas as cinco melhores formulações e analisadas por meio do teste de ordenação por preferência variando as concentrações de tegumento e PTS. O tegumento e farelo apresentaram conteúdo de fibras de $74,09 \%$ e $30,69 \%$, respectivamente. Os resultados das análises microbiológicas da sopa estão de acordo com legislação vigente. Das cinco formulações submetidas ao teste sensorial, a formulação F3, com proporções iguais de tegumento e farelo, apresentou melhores características e 77\% de aceitação global. Conclui-se que os subprodutos da extração de amido de feijão podem ser utilizados com potencial tecnológico no preparo de misturas prontas para sopas.
\end{abstract}

Palavras-chave: feijão; extração de amido; subproduto; mistura pronta para sopa.

\section{Introdução}

A indústria de alimentos gera grande quantidade de resíduos que podem resultar em sérios danos ambientais, caso não sejam aproveitados ou tratados de forma adequada. No final do século XX a sociedade reconheceu que os padrões de produção e consumo haviam alcançado níveis insustentáveis. A partir de então, todos os setores da economia vem desenvolvendo processos e tecnologias que visam à produção mais limpa. Dentro desse contexto, a valorização de subprodutos tem sido amplamente estudada, principalmente os da agroindústria, que têm sido elevados à condição de ingredientes devido ao elevado valor nutricional (CANTERI et al, 2008). 
O feijão (Phaseolus vulgaris L.) em grão é uma das principais fontes de proteína e um dos alimentos mais importantes para a população brasileira. É adquirido geralmente na forma de grãos secos e crus e, comparado a outros alimentos de consumo cotidiano, precisa de longo período de cocção para seu preparo, o que o torna pouco competitivo (CARNEIRO, 2001 ; VALE, 2010). As alterações nos hábitos alimentares, no estilo de vida e a valorização econômica do trabalho da mulher, são fatores que levam o consumidor a optar por produtos que apresentem praticidade e/ou rapidez no preparo (CARNEIRO, 2001).

Durante a estocagem dos grãos ocorre deterioração do produto em si, a qual é gradativa, irreversível e cumulativa. A velocidade de deterioração depende do ambiente, da composição química e da condição física dos grãos no inicio do armazenamento. Essa perda de qualidade caracteriza-se por mudanças no sabor, escurecimento do tegumento dos grãos em cultivares com coloração clara (classe cores) e aumento do grau de dureza dos grãos, o que resulta em aumento do tempo de cozimento (DELFINO; CANNIATTI-BRZACA, 2010). Feijões endurecidos devido a condições impróprias de armazenamento têm sua qualidade e aceitabilidade afetadas.

Para a utilização dos grãos endurecidos Hard to cook (HTC) é necessário o aprimoramento dos processos tecnológicos que possam ser aplicados para transformação desses feijões de qualidade inferior em produtos de interesse comercial (RIBEIRO, 2005; RUIZ et al., 2010). A utilização de alternativas tecnológicas como descascamento, maceração em soluções salinas, fermentação, extrusão, produção de isolados e concentrados proteicos e a extração de amido podem melhorar o valor nutricional de dietas e reduzir as perdas anuais de feijões endurecidos (RIBEIRO et al., 2009). O consumo industrial de feijão tem aumentado, devido ao seu uso como ingrediente em sopas e alimentos desidratados (OLIVEIRA, 1996).

Diante do exposto, o objetivo deste trabalho foi desenvolver uma mistura para o preparo de sopa utilizando o farelo e o tegumento resultantes do processo de extração do amido de feijão comum (Phaseolus vulgaris L.).

\section{Material e métodos}

\section{Obtenção do tegumento e do farelo}

O tegumento e o farelo utilizados neste trabalho foram extraídos do amido de feijão comum (Phaseolus vulgaris L.). O feijão utilizado foi o comum do cultivar IPR 139 da classe "cores" proveniente da safra 2011/2012, o qual é conhecido popularmente como feijão carioca.

Os grãos de feijão foram macerados em água a temperatura de $4{ }^{\circ} \mathrm{C}$ durante 12 horas, a água de remolho foi descascada, em seguida foi realizada a retirada do tegumento manualmente. O tegumento e os cotilédones foram secos em estufa com circulação de ar Tecnal modelo TE394/1. A 
$40^{\circ} \mathrm{C}$ durante 24 horas. O tegumento foi armazenado em embalagens plásticas e mantido a temperatura ambiente até o momento da sua utilização.

Os cotilédones foram moídos em Moinho TecMill modelo TE-633 da Marca Tecnal e procedeu-se a extração do amido. Na etapa de separação de subproduto e amido utilizando peneiras de Mesh 270, abertura de $\mathrm{mm} / \mu \mathrm{m}$, resulta em um subproduto fibroso retido nas peneiras, este farelo foi seco em estufa com circulação de ar Tecnal modelo TE394/1 por 24 horas. Armazenado em embalagens plásticas e mantido a temperatura ambiente até o momento da utilização.

O tegumento e o farelo obtidos da extração de amido de feijão foram moídos em Moinho TecMill modelo TE-633 da Marca Tecnal por duas vezes consecutivas. Depois, para conferir uma granulometria mais fina às farinhas resultantes, foram moídos por mais três vezes consecutivas em Moinho M20 da Marca IKA®, peneirados em Tamis de malha, Mesh 42, abertura em mm/ $\mu \mathrm{m} 355$, e embalados em sacos plásticos selados.

\section{Composição química do tegumento e do farelo}

Para a análise da composição química do farelo e do tegumento foram realizadas determinação de umidade, cinzas, proteínas, extrato etéreo e fibra alimentar seguindo-se a metodologia indicada pela a AOAC (2006).

\section{Desenvolvimento da formulação e planejamento experimental}

$\mathrm{Na}$ formulação da sopa, os teores de farinha de tegumento e farelo de feijão e de proteína texturizada de soja (PTS) foram definidos por planejamento experimental, Tabela 01, perfazendo um total de 59\% da formulação. O teor de macarrão instantâneo (Marca Nissin) (25\%), soro de leite (Marca Alibra) (8\%) e tempero pronto (Marca Arisco) (8\%) foram mantidos constantes durante todo o experimento. A formulação inicial foi adaptada de Santos et al. (2010).

As proporções do tegumento e farelo de feijão de do PTS foram determinadas a partir de um planejamento experimental de mistura para três componentes utilizando o modelo em rede simplex $\{3,2\}$ aumentado com pontos interiores, de acordo com o software Statistica 6.0 (Tabela 01), resultando em dez formulações (Tabela 1). Os limites máximo e mínimo para cada ingrediente foram estabelecidos a partir de um ensaio prévio, onde concentrações de tegumento, farelo e PTS variaram de 9,83 a 39,33\% e foram testadas em uma formulação adaptada de Santos et al. (2010). 
Tabela 1 - Planejamento experimental de mistura variando teores de farelo, tegumento e PTS em proporções reais dos ingredientes na mistura e em pseudocomponentes.

\begin{tabular}{lcccccc}
\hline \multirow{2}{*}{ Formulação } & \multicolumn{5}{c}{ Proporções dos ingredientes nas misturas ternárias } \\
\cline { 2 - 7 } & Farelo & Tegumento & PTS & Farelo & Tegumento & PTS \\
\cline { 2 - 7 } & 36 & 0 & 0 & 1,000 & 0,000 & 0,000 \\
1 & 3,6 & 32,4 & 0 & 0,000 & 1,000 & 0,000 \\
3 & 3,6 & 0 & 32,4 & 0,000 & 0,000 & 1,000 \\
4 & 18 & 18 & 0 & 0,500 & 0,500 & 0,000 \\
5 & 18 & 0 & 18 & 0,500 & 0,000 & 0,500 \\
6 & 3,6 & 16,2 & 16,2 & 0,000 & 0,500 & 0,500 \\
7 & 12 & 12 & 12 & 0,333 & 0,333 & 0,333 \\
8 & 24 & 6 & 6 & 0,667 & 0,167 & 0,167 \\
9 & 6 & 24 & 6 & 0,167 & 0,667 & 0,167 \\
10 & 6 & 6 & 24 & 0,167 & 0,167 & 0,667 \\
\hline
\end{tabular}

A avaliação sensorial global foi avaliada como resposta utilizando o modelo linear.

O modelo matemático ajustado para a resposta foi submetido a análise de variância (ANOVA) para determinar a significância do modelo de regressão em nível de 5\% (teste F) e o coeficiente de determinação ajustado ( $\mathrm{R}^{2}$ ajustado). Para obtenção do planejamento experimental as análises dos dados e construção de gráfico utilizou-se o software Statistic 6.0.

\section{Análise microbiológica}

As análises microbiológicas das sopas foram realizadas de acordo com os padrões a exigidos pela RDC $n^{\circ} 12$ (2001). Em misturas ou pós para preparo de sopas as análises obrigatórias são Bacillus cereus, Coliformes a $45^{\circ} \mathrm{C}$ e Salmonella sp. Segundo a legislação, a mistura para sopa é um produto que deve ser consumido após cozimento com adição de líquido (mínimo $75{ }^{\circ} \mathrm{C} / 20 \mathrm{~s}$ ). As análises foram realizadas de acordo com a Instrução Normativa nº 62 (Brasil, 2003).

\section{Avaliação sensorial}

A avaliação sensorial global das 10 misturas de sopas foi realizada no Laboratório de Análise Sensorial na Universidade Estadual de Ponta Grossa com os membros da equipe. Às formulações foram atribuídas notas de 0 a $10(0=$ desgostei muitíssimo; e 10 = gostei muitíssimo $)$ para cada formulação em relação aos atributos: cor, odor, textura e sabor, gerando uma nota para cada formulação. Com o resultado desta análise foram desenvolvidas cinco formulações fixando o teor de farelo de feijão e variando o tegumento e a PTS (Tabela 2).

No teste de ordenação de preferência participaram 50 avaliadores não treinados, onde classificaram em ordem crescente as amostras segundo a sua preferência. 
Com o resultado do teste de ordenação de preferência foi realizado o teste de aceitação através da escala hedônica de nove pontos, de acordo com a metodologia do Instituto Adolfo Lutz (2008).

Tabela 2 - Formulações para análise sensorial de ordenação de preferência.

\begin{tabular}{lccccc}
\hline \multicolumn{1}{c}{ Ingredientes $(\mathbf{g})$} & F1 & F2 & F3 & F4 & F5 \\
\hline Tegumento de feijão & 6 & 4,5 & 3 & 1,5 & 0 \\
Farelo de feijão & 30 & 30 & 30 & 30 & 30 \\
PTS (Jasmine) & 0 & 1,5 & 3 & 4,5 & 6 \\
Macarrão instantâneo (Nissin) & 15 & 15 & 15 & 15 & 15 \\
Soro de leite em pó (Alibra) & 5 & 5 & 5 & 5 & 5 \\
Tempero pronto (Maggi) & 5 & 5 & 5 & 5 & 5 \\
\hline
\end{tabular}

O trabalho foi previamente aprovado pelo Comitê de Ética e Pesquisa da UEPG (número CAAE 07802512.1.0000.0105).

\section{Resultados e Discussão}

Composição centesimal do farelo e tegumento de feijão e da proteína texturizada de soja (PTS)

Os resultados da análise centesimal do farelo e tegumento do feijão e da PTS podem ser visualizados na Tabela 3 .

Tabela 3 - Composição química dos resíduos (tegumento e farelo) da extração de amido de feijão.

\begin{tabular}{lccccc}
\hline Análise & \multicolumn{2}{c}{ Tegumento } & \multicolumn{2}{c}{ Farelo } & PTS \\
\hline & Média & Desvio Padrão & Média & Desvio Padrão & \\
\hline Proteína (\%) & 6,24 & $\pm 0,18$ & 20,17 & $\pm 2,032$ & 52,00 \\
Lipídeo (\%) & 0,49 & $\pm 0,28$ & 1,58 & $\pm 0,171$ & n.a. \\
Cinzas (\%) & 4,29 & $\pm 0,03$ & 1,65 & $\pm 0,038$ & n.a. \\
Umidade (\%) & 9,94 & $\pm 1,38$ & 8,84 & $\pm 0,983$ & n.a. \\
Fibra alimentar $(\%)$ & 74,09 & $\pm 0,72$ & 30,69 & $\pm 3,515$ & 14,00 \\
n.a.: não analisado & \multicolumn{5}{c}{}
\end{tabular}

Os valores de proteína determinados no tegumento e farelo de feijão foram de 6,2 e $20,2 \%$, respectivamente, resultados estes que proporcionam ao produto final um alto conteúdo de proteína.

A concentração de lipídeos encontrada no tegumento e no farelo de feijão foi de 0,5 e $1,5 \%$, respectivamente, indicando um baixo conteúdo desses compostos no produto final.

O tegumento do feijão apresentou um teor de fibra alimentar de 74,09\% enquanto o farelo apresentou 30,69\%. De acordo com Brasil (1998) as fibras alimentares auxiliam o funcionamento do intestino. Seu consumo deve estar associado a uma alimentação equilibrada e hábitos de vida saudáveis. Na tabela de informação nutricional de embalagens de alimentos processados deve ser declarada a quantidade de fibras alimentares. O consumo deste constituinte deve ser acompanhado da ingestão de líquidos. A alegação de "Fonte de Fibra Alimentar" pode ser utilizada desde que a porção do produto pronto para consumo forneça no mínimo $3 \mathrm{~g} / 100 \mathrm{~g}$ de fibras se o alimento for 
sólido ou 1,5 g/100 mL de fibras se o alimento for líquido. A alegação de "Alto Teor de Fibra Alimentar", por sua vez, pode ser utilizada desde que a porção do produto pronto para consumo forneça no mínimo $6 \mathrm{~g} / 100 \mathrm{~g}$ de fibras se o alimento for sólido ou $3 \mathrm{~g} / 100 \mathrm{~mL}$ de fibras se o alimento for líquido.

Assim, essas matérias-primas podem contribuir para o incremento de proteína e fibra alimentar na dieta das pessoas que consumirem a sopa.

\section{Análises microbiológicas}

As análises microbiológicas da sopa apresentaram resultados dentro do padrão exigido pela legislação vigente, (Tabela 4). Comprovando, desta maneira, a qualidade microbiológica deste produto para uso alimentar.

Tabela 4. Resultados das análises microbiológicas da sopa

\begin{tabular}{lll}
\hline Análise & Resultado & Padrão* \\
\hline Bacillus cereus $/ \mathrm{g}$ & Ausência & $3 \times 10^{3}$ \\
Coliformes à $45^{\circ} \mathrm{C} / \mathrm{g}$ & $2 \times 10^{1}$ & $10^{2}$ \\
Salmonella $\mathrm{sp} / 25 \mathrm{~g}$ & Ausência & Ausência \\
\hline Padrão de acordo com RDC n ${ }^{\circ} 12,2001$ (Brasil, 2001) &
\end{tabular}

\section{Desenvolvimento da formulação e análise estatística}

$\mathrm{Na}$ avaliação sensorial global foi observado que o aumento das notas foi proporcional à concentração de farelo de feijão, ou seja, a amostra que apresentou maior nota foi a que continha maior proporção de farelo de feijão (Figura 1). O modelo ajustado foi significativo ( $\mathrm{p}=0,0037$ ) e o coeficiente de determinação ajustado foi de $74 \%$ e a equação do modelo matemático é preditiva.

$$
\begin{aligned}
& \mathbf{y}=+9,74 * x 1+2,74 * x 2+3,41 * x 3+0 \\
& \text { onde, } x 1=\text { farelo; } x 2=\text { tegumento e } x 3=\text { PTS. }
\end{aligned}
$$

\section{Teste de ordenação de preferência}

Comparando-se os módulos da diferença com a DMS (diferença mínima significativa) podese dizer que houve diferença estatística significativa ao nível de 5\%, entre as formulações F3 - F5; F3 - F4; F1 - F4 e F4 - F2.

A formulação F3 obteve maior preferência entre os avaliadores, devido ao sabor, cor, textura e aparência geral apresentada. Tais características sensoriais provavelmente foram proporcionadas pelos dois ingredientes de interesse, ou seja, tegumento e farelo, que foram 
variados na mesma proporção, esta formulação foi selecionada para realizar o teste de aceitação através da Escala Hedônica.

Figura 1 - Avaliação sensorial

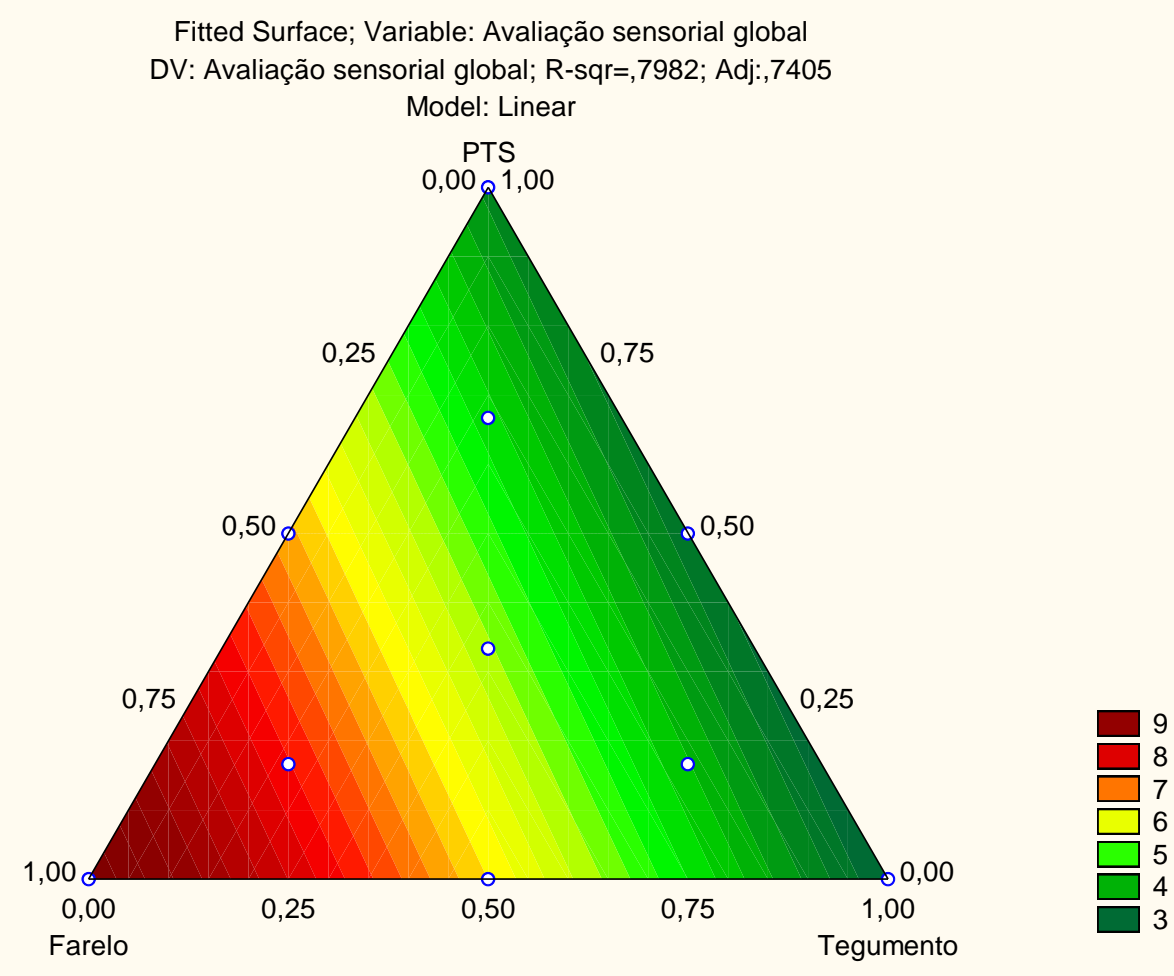

Software Statistic 6.0

Escala hedônica e intenção de compra

Dos $100 \%$ dos avaliadores que participaram do teste de aceitação, $80 \%$ se enquadram na faixa etária de 18 a 30 anos de idade. Em relação à frequência de consumo de sopa pronta, $82 \%$ consomem o produto esporadicamente. Quanto ao consumo de feijão $76 \%$ informaram que consomem diariamente e 58\% dos avaliadores informaram consumir fibras diariamente.

Foi oferecida aos avaliadores a amostra F3 para realizar a análise de aceitação. A aceitação global da F3 foi de 77\%. De acordo Dutcosky (2013) o índice de aceitação deve ser maior que $75 \%$, portanto, formulação foi aceita pelos avaliadores. Na Figura 2, pode ser observada a frequência de intenção de compra dos avaliadores. 
Figura 2: Intenção de compra dos consumidores

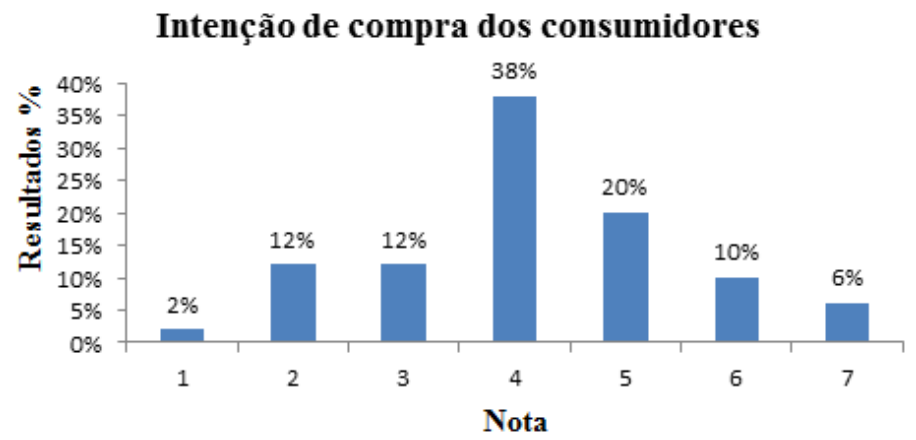

Da totalidade dos consumidores, $36 \%$ comeriam a sopa frequentemente a sempre e $38 \%$ comeriam ocasionalmente. Esse resultado pode ser devido ao fato da sopa ser um alimento de consumo esporádico.

\section{Conclusão}

A mistura pronta para sopa desenvolvida com farelo e tegumento de feijão apresentou resultados favoráveis, o modelo ajustado foi significativo $(\mathrm{p}=0,0037)$ e o coeficiente de determinação ajustado foi de 74\% e a equação do modelo matemático é preditiva. Mostrando-se um produto potencial para comercialização devido aos valores de aceitação e intenção de compra obtidos na análise sensorial. Os ingredientes desse produto demostram alto valor nutricional devido ao conteúdo de fibras e proteínas. Além de contribuir para o consumo de fibras diárias necessárias à manutenção da saúde, este produto valoriza uma leguminosa que está perdendo espaço na mesa dos consumidores, uma vez que o tempo de preparo desta sopa é reduzido, de aproximadamente 15 minutos com aproveitamento de subprodutos da extração de amido de feijão.

\section{Referências}

BRASIL, Resolução - Resolução RDC n 273, de 22 de setembro de 2005. Regulamento técnico para misturas para o preparo de alimentos e alimentos prontos para o consumo. Ministério da Saúde. Brasília, 2005.

BRASIL, Instrução Normativa $N^{\circ}$ 62, de 26 de agosto de 2003. Oficializa os Métodos Analíticos Oficiais para Análises Microbiológicas para Controle de Produtos de Origem Animal e Água. Ministério da Agricultura, Pecuária e Abastecimento. Brasília, 2003.

BRASIL, Resolução - RDC $\mathrm{n}^{\mathbf{0}}$ 12, de 2 de janeiro de 2001. Aprovar o regulamento técnico sobre padrões microbiológicos para alimentos. Ministério da Saúde. Brasília, 2001.

BRASIL, Portaria $n^{\circ} 27$, de 13 de janeiro de 1998. Regulamento técnico referente à informação nutricional complementar. Ministério da Saúde. Brasília, 1998.

CANTERI, M. H. G.; LOSS, E.; BARANA, A. C. Breve panorama do gerenciamento de resíduos sólidos em indústrias alimentícias no Brasil. VI Semana de Tecnologia de Alimentos. v. 02, n. 34, 2008.

CARNEIRO, J. C. S. (2001). Processamento industrial de feijão, avaliação sensorial descritiva e mapa de preferência. Dissertação de Mestrado. Viçosa, Univ. Fed. de Viçosa. 90p. 
DELFINO, R. A.; CANNIATTI-BRAZACA, S. G. Interação de polifenóis e proteínas e o efeito na digestibilidade proteica de feijão comum (Phaseolus vulgaris L.) cultivar Pérola. Ciência e Tecnologia de Alimentos, v. 30, n. 02, p. 308-312, 2010. http://dx.doi.org/10.1590/S0101-20612010000200003

DUTCOSKY, Silvia Deboni. Análise sensorial de alimentos. 4. ed. rev. ampl. Curitiba: Champagnat, 2013. 531 p.

LUSTOSA, B. H. B.; LEONEL, M.; MISCHAN, M. M. Influência de parâmetros de extrusão na absorção e solubilidade em águas de farinhas pré-cozidas de mandioca e caseína. Revista Alimentos e Nutrição. V. 20, n. 2, p. 223-229, abr/jun.2009.

RIBEIRO, H. J. S. S., FERREIRA, S. H. P.; MIYAGUI, D. T. Propriedades físicas e químicas de feijão comum preto, cultivar iapar 44, após envelhecimento acelerado. Ciência e Tecnologia de Alimentos, v. 25, n. 1, p. 165-169, 2005. http://dx.doi.org/10.1590/S0101-20612005000100027

RIBEIRO, H. J. S. S.; PRUDENCIO, S. H.; MIYAGUI, D. T.; RIBEIRO, E. L. A. Caracterização de concentrado proteico de feijão comum preto, cultivar Iapar 44, novo e envelhecido. Ciência e Tecnologia de Alimentos, v. 29, n. 3, p. 571-580, 2009. http://dx.doi.org/10.1590/S0101-20612009000300019

RUIZ-RUIZ. J.; DÁVILA-ORTÍZ, G.; CHEL-GUERRERO L. A.; BETANCUR-ANCONA, D. A. Wet Fractionation of Hard-to-Cook Bean (Phaseolus vulgaris L.) Seeds and Characterization of Protein, Starch and Fibre Fractions. Food Bioprocess Technology. v. 05, n. 05, p. 1531-1540, 2012. http://dx.doi.org/10.1007/s11947-010-0451-0

SANTOS, A. P.; REBOUÇAS, T. N. H.; SOUZA, J. C. C.; BONOMO, R. C. F.; SILVA, L. M. Caracterização e avaliação da qualidade de sopas desidratadas elaboradas com farinha de batata durante o tempo de armazenamento. Boletim do CEPPA, v. 28, n. 1, p. 57-68, 2010.

VAlE, N. M.; BARILI, L. D.; ROCHA, F.; PREZZI, H. A.; ALMEIDA, C. B.; COIMBRA, J. L. M.; GUIDOLIN, A. F. Adição de sal na água de hidratação reduz o tempo de cozimento em feijão comum ao longo do tempo de armazenamento. Alimentos e Nutrição, v. 21, n. 4, p. 617-623, 2010.

Submetido em 10 jul. 2014, Publicado em 28 dez. 2014. 